\title{
KERNEL-BASED VIRTUAL MACHINE UNTUK VIRTUALISASI DATABASE SEBAGAI SOLUSI KEBUTUHAN PERANGKAT KERAS STUDI KASUS IMPLEMENTASI SISTEM INFORMASI KLINIK KECANTIKAN
}

\author{
(Kernel-Based on Virtual Machine for Virtual Database as a Solution \\ for the Need of Hardware A Case Study of Information System \\ Implementation in Beauty Clinic) \\ Whisnumurti Adhiwibowo \\ Fakultas Teknologi Informasi dan Komunikasi Universitas Semarang
}

\begin{abstract}
Information System Development is needed by companies which have business orientation expecially a company focusing in service. Beauty clinic is a company focusing in service. The need of information system is difficult to avoid, because an excellent and optimal service are one of the main modals in beauty clinic business. One of the obstacles that rises in information system development in beauty clinic is when a new information system implementation is done followed by minimum budget to provide new equipments and hardwares. Financial constraints in providing hardware will be an obstacle in information system implementation. There are some ways to overcome the lack of hardware, such as rentaling server hardware, rentaling virtual server with its internet connection or by doing computer virtualisation server that exists. One way to do saving money in budgeting is by doing computer virtualisation server.
\end{abstract}

Keywords : Virtualization, Virtual Machine, KVM, Beauty Clinic

\section{PENDAHULUAN}

\subsection{Latar Belakang}

Pembangunan sistem informasi, banyak dibutuhkan bagi perusahan-perusahan yang berorientasi kepada bisnis terutama perusahaan yang mengutamakan pelayanan. Klinik kecantikan merupakan salah satu bisnis yang berfokus kepada pelayanan dan jasa. Kebutuhan sistem informasi merupakan hal yang sulit untuk dihindari, karena pelayanan yang prima dan optimal merupakan salah satu faktor utama dalam bisnis kecantikan.

Salah satu kendala yang muncul dalam pembangunan sistem informasi klinik kecantikan adalah minimnya dana untuk pengadaan peralatan atau perangkat keras terutama perangkat keras server baru yang relatif memiliki harga mahal. Ada berbagai cara untuk mengatasi kendala minimnya perangkat keras seperti melakukan sewa perangkat keras server, sewa virtual server beserta koneksi internetnya atau melakukan virtualisasi komputer server yang ada.

Keterbatasan dana dalam pengadaan perangkat keras baru untuk klinik kecantikan yang disebabkan minimnya anggaran dan telah ketersediaan perangkat keras existing untuk sistem aplikasi existing menjadikan pengkondisian penggunaan perangkat keras existing untuk diparalelkan atau digabungkan dengan sistem informasi yang baru. Salah satu hal yang mungkin adalah melakukan virtualisasi komputer server existing. Virtualisasi komputer server yang dilakukan adalah melakukan pembagian sumber daya perangkat keras server existing untuk 
digunakan atau dibagi kepada sistem inforamsi baru dan sistem aplikasi existing.

\subsection{Perumusan Permasalahan}

Berdasarkan latar belakang diatas maka perumusan permasalahan yang ada adalah

1. Bagaimana merancang dan membangun virtualisasi server yang akan digunakan untuk sistem informasi klinik kecantikan dengan keterbatasan perangkat keras.

2. Bagaimana mengimplementasikan virtualisasi server dengan menerapkan kernel-based virtual machine untuk implementasi beberapa sistem informasi dan operating sistem yang berbeda.

\subsection{Tujuan Penelitian}

Tujuan yang akan dicapai dalam penelitian ini adalah

1. Merancang dan membangun virtual private server yang akan digunakan untuk implementasi sistem informasi klinik kecantikan.
2. Mengimplementasikan virtualisasi server dengan menerapkan kernel-based virtual machine untuk implementasi beberapa sistem informasi dan operating sistem yang berbeda

\subsection{Metode Penelitian}

Penelitian ini merupakan sebuah penelitian penerapan sistem dengan mengimplementasikan sistem virtualisasi server terhadap server existing. Metode yang digunakan adalah metode re-engineering. Dengan merubah operating sistem utamanya yang digunakan oleh perangkat keras server existing. Operating sistem server existing, akan diganti dengan operating sistem baru yang akan digunakan sebagai operating sistem virtualisasi. Operating sistem yang akan digunakan untuk penelitian ini adalah proxmox.

Proxmox memiliki 2 pemodelan untuk virtulalisasi yaitu model KVM dan OpenVZ. Model yang akan digunakan dalam penelitian ini adalah model KVM. Ilustrasi model KVM yang akan digunakan dapat diillustrasikan berikut ini :

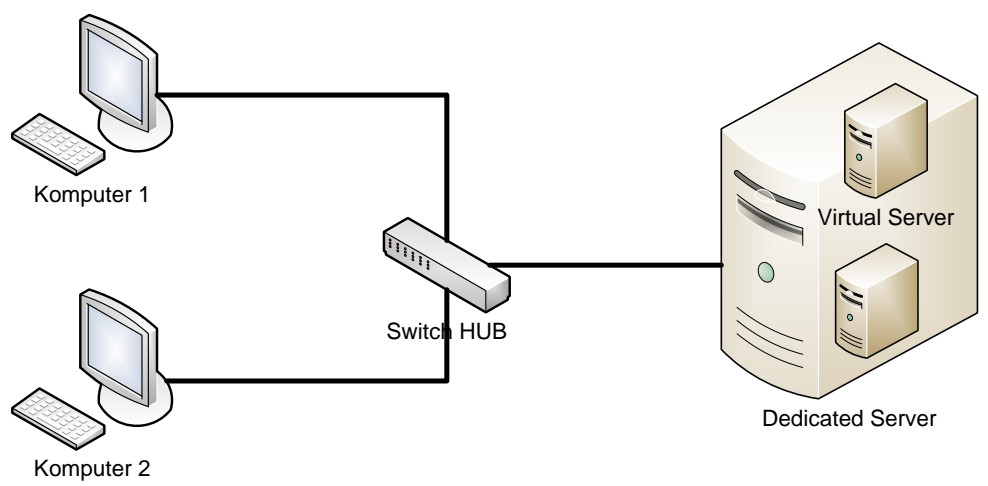

Gambar 1. Virtualisasi Server.

Server virtual dibangun didalam server dedicated atau existing sehingga jika dilihat dari bentuk fisiknya, hanya berupa satu buah server. Didalam server tersebut terdapat virtual server yang tentunya, perancangan dan pembangunannya disesuaikan dengan kebutuhan dari sistem yang akan diimplimentasikan yaitu dua sistem dengan dua operating sistem yang berbeda.

\section{STUDI PUSTAKA}

Menurut Tito dalam penelitiannya, Software virtualisasi melakukan abstraksi dari mesin virtual dengan cara menambahkan layer baru di antara 3 layer di atas [12]. Posisi dari layer baru tersebut menentukan level dari virtualisasi. Secara umum terdapat 3 level virtualisasi [5], yaitu :

1. Virtualisasi Level Hardware 
Adalah layer virtualisasi yang diletakkan di atas layer hardware, (telah dibuat oleh IBM) berfungsi menyediakan layanan servis virtualisasi. Perangkat keras tersebut dapat dipartisi/dibagi resource-nya sehingga masingmasing resource dapat menjalankan sistem operasi dan aplikasinya sesuai kebutuhan. Arsitektur komputer untuk virtualisasi pada level hardware dapat disebut sebagai arsitektur hypervisor.

2. Virtualisasi Level Sistem Operasi

Adalah layer virtualisasi yang berada di atas layer sistem operasi. Sistem operasi dan program aplikasi dijalankan di atas mesin virtual. Untuk mengakses ke perangkat keras dari mesin virtual dapat melalui sistem operasi dari mesin fisik. Arsitektur pada level sistem operasi ini disebut sebagai arsitektur hosted.

3. Virtualisasi Level Aplikasi

Adalah layer virtualisasi yang diletakkan diprogram aplikasi, digunakan untuk abstraksi mesin virtual yang menjalankan program atau aplikasi yang disesuaikan dengan pendefinisian abstraksi mesin virtual yang akan menjalankan program atau aplikasi tersebut.

Selain dari level virtualisasi, ada dua pendekatan cara virtualisasi menurut Jones yaitu hardware emulation dan operating system-level virtualization. Dari penelitian Adam dan Ageesen yang juga mencari perbedaan kinerja yang dihasilkan oleh teknik virtualisasi [4] menyebutkan adanya 2 pendekatan yaitu full virtualization dan hardware-assisted virtualizated. Sedangkan menurut Tito, vitualisasi terbagi menjadi 2 teknologi vitualisasi [12], Container Virtualization dan Full Virtualization. Pendapat ini berdasarkan acuannya kepada Proxmox.

Proxmox merupakan software open source virtualization platform untuk menjalankan Virtual Appliance and Machine. Promox adalah operating sistem linux yang digunakan untuk melakukan virtualisasi ataupun clustering. Beberapa fitur proxmox yang dijabarkan oleh Tito[12], yaitu

- Bare-metal ISO installer
Proxmox menginstall sistem operating secara lengkap dan sistem manajemennya. "Bare-metal" memiliki arti instalasi dimulai dari kondisi server empty dan tidak perlu dilakukan instalasi sistem operasi awal/dasar.

- Central Web-based management

Promox tidak membutuhkan instalasi alat manajemen secara terpisah, karena semua dapat dilakukan melalui web browser yang telah terkoneksi ke Server Proxmox..

- Backup-Restore-Live Migration Kemampuan lain dari Proxmox adalah fasilitas menggunakan VZDump (sebuah utilitas/tool untuk membuat snapshot dalam menjalankan dan mengoperasionalkan Virtual Machines.

- Cluster

Fitur cluster ini memungkinkan untuk melakukan manajemen server fisik, yang terdiri dari satu master dan beberapa node (minimum satu node). Fitur cluster terdiri dari web manajemen terpusat, untuk mengakses node dan guest, console digunakan melihat semua virtual machine, migrasi dari virtual machine antara virtual appliance template store dan physical hosts yang tersinkronisasi.

\section{PERANCANGAN SISTEM}

\subsection{Desain Server Virtual}

Virtual private server (VPS) akan dibangun didalam server operasional atau server existing. Komputer server akan memberikan alokasi resource secara dynamic kepada virtual private server dengan nilai maksimal resource yang telah ditentukan. Kebutuhan alokasi resource bergantung kepada sistem operating yang diletakkan dalam VPS. Kebutuhan standart untuk resource dapat dilihat dari kebutuhan minimum operating sistem tersebut.

Dalam server tersebut terdapat virtual private server yang akan digunakan untuk meletakkan sistem lama dan sistem informasi baru yang sedang diimplemtasikan. Penggambaran sistem yang akan dibangun dapat dilihat pada gambar berikut : 


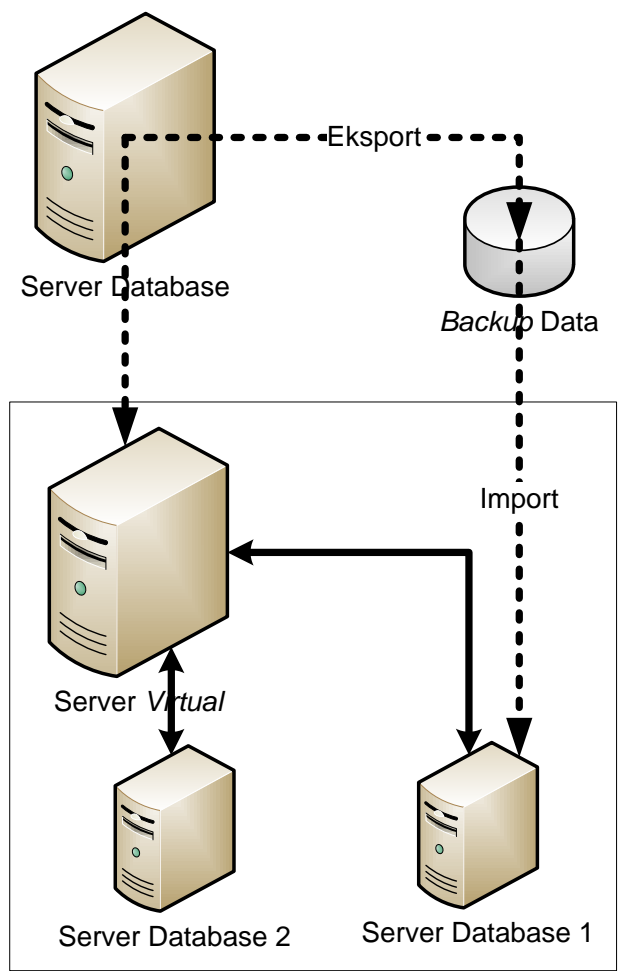

Gambar 2. Ilustasi implementasi server existing

Dari ilustrasi dapat digambarkan bahwa server existing akan diubah menjadi server virtual dengan menggunakan Sistem Operasi Proxmox yang based operating system-nya adalah Linux. Kebutuhan perangkat keras untuk Sistem Operasi Poxmox sebagai vitualisasi server adalah prosessor Intel Xeon. Sedangkan untuk RAM, VGA dan Hardisk disesuaikan dengan kebutuhan VPS yang akan dibangun.

Pembuatan virtual private server akan menggunakan model KVM (Kernel-based Virtual Machine) dikarenakan KVM mendukung virtualisasi secara penuh. Kebutuhan pembangunan virtual private server dengan KVM membutuhkan file operating system ber-extensi iso.

\subsection{Desain LAN}

Pembuatan virtual private server dengan KVM yang mendukung virtualisasi secara penuh perangkat keras akan mempermudah dalam membangun pengalamatan networking. Desain networking dibangun dengan menggunakan pengalamatan IP address kelas C. Jaringan komputer yang digunakan hanya untuk kebutuhan intranet dan tidak terhubung dengan internet. Pembangunan ini dilakukan dalam satu kantor yang tidak terhubung internet dan tidak menggunakan Wifi. 


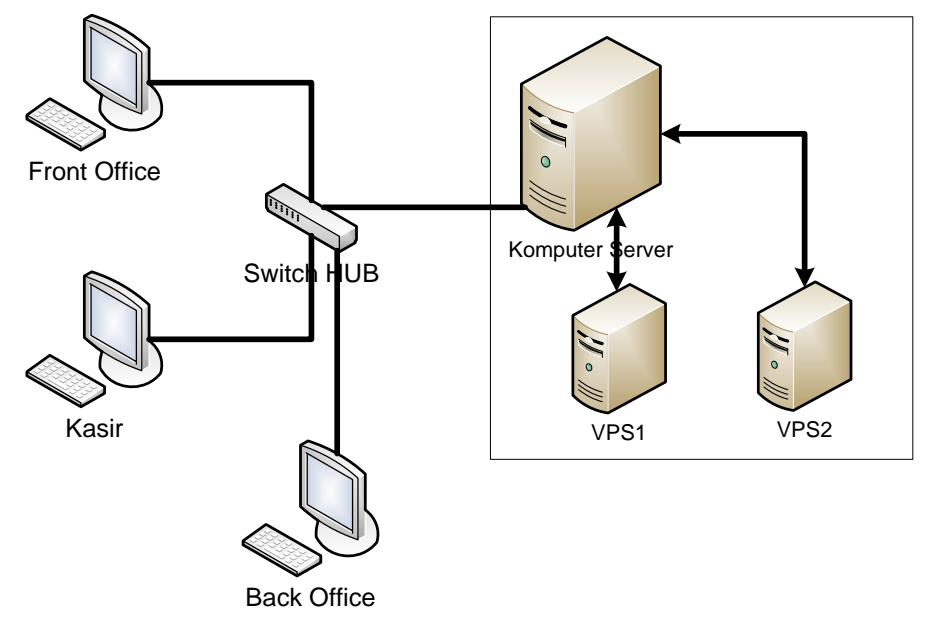

Gambar 3. Ilustasi desain networking komputer

\section{IMPLEMENTASI SISTEM DAN hardisk, untuk itu sebelum melakukan instalasi PEMBAHASAN \\ 4.1. Implementasi Server Virtual \\ maka perlu dilakukan back-up seluruh data server.}

Pembanguan atau implementasi server virtual dilakukan dalam beberapa tahapan seperti :

a. Backup data server

Operating System Proxmox dalam instalasinya secara otomatis akan menghapus seluruh isi hardisk dan akan menformat ulang

Sistem aplikasi existing menggunakan database MySql sehingga perlu dilakukan dibackup terlebih dahulu. Backup database dapat menggunakan Phpmyadmin melalui browser atau tool bantuan lainnya seperti ExImMysql.

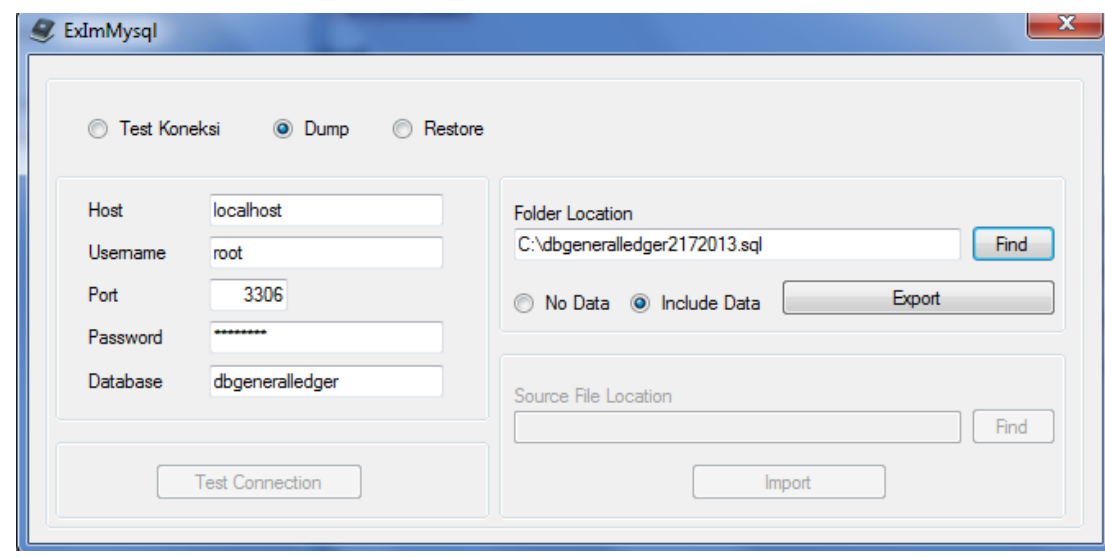

Gambar 4 . Backup database menggunakan ExImMysql

Hasil dari backup dan data penting lainnya harus dipindahkan dari komputer server agar tidak ikut terformat Proxmox.

b. Server Virtual

Setelah Proxmox terinstal yang perlu diperhatikan adalah pemberian alamat komputer atau IP address kepada komputer server tersebut. Karena komputer server yang digunakan tidak diperuntukkan untuk koneksi internet maka gateway atau DNS dapat diabaikan. IP address yang digunakan untuk pengalamatan Proxmox merupakan IP address yang akan diakses oleh komputer klien untuk membangun virtual private server. Gunakan browser dari komputer klien untuk 
melakukan akses terhadap komputer server melalui port 8006.

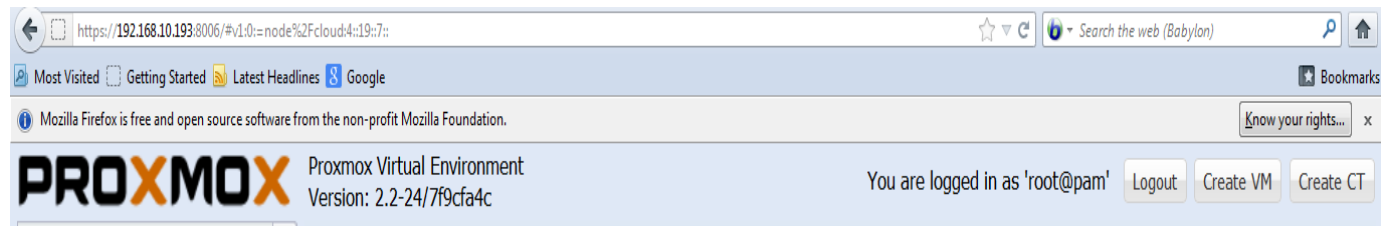

Gambar 5. Koneksi Proxmox melalui komputer klien

Setelah komputer klien dapat terkoneksi kebutuhan sistem. Penggunaan resource dengan komputer server, maka virtual private untuk virtual private server untuk sistem server dapat diinstal. Kebutuhan untuk virtual exisitng dengan sistem baru dapat dilihat dari private server harus diperhitungkan dari total tabel berikut :

resource total perangkat keras server dan

Tabel 1. Resource virtual private server

\begin{tabular}{|l|l|l|l|}
\hline \multicolumn{1}{|c|}{ Jenis } & Komputer Server & VPS1 (Sistem Lama) & VPS2 (Sistem Baru) \\
\hline Prosessor & Xeon & Pentium III & Dual core \\
\hline RAM & $4 \mathrm{MB}$ & $1 \mathrm{MB}$ (dynamic) & 2 MB (dynamic) \\
\hline Hardisk & $80 \mathrm{~GB}$ & $16 \mathrm{~GB}$ & $32 \mathrm{~GB}$ \\
\hline Os & Proxmox & Window Xp & Ubuntu \\
\hline
\end{tabular}

Tiap-tiap virtual private server akan diinstal sistem operasi, yang disesuaikan untuk kebutuhannya. Dari tabel 1 terlihat bahwa VPS1 yang diperuntukkan untuk sistem exisitng akan digunakan Window Xp dan VPS2 yang diperuntukkan untuk implementasi sistem baru digunakan Linux Ubuntu versi 12. Instalasi dilakukan melalui browser dengan menggunakan file dengan extensi iso. Hasil Instalasi dapat dilihat dari browser berikut :

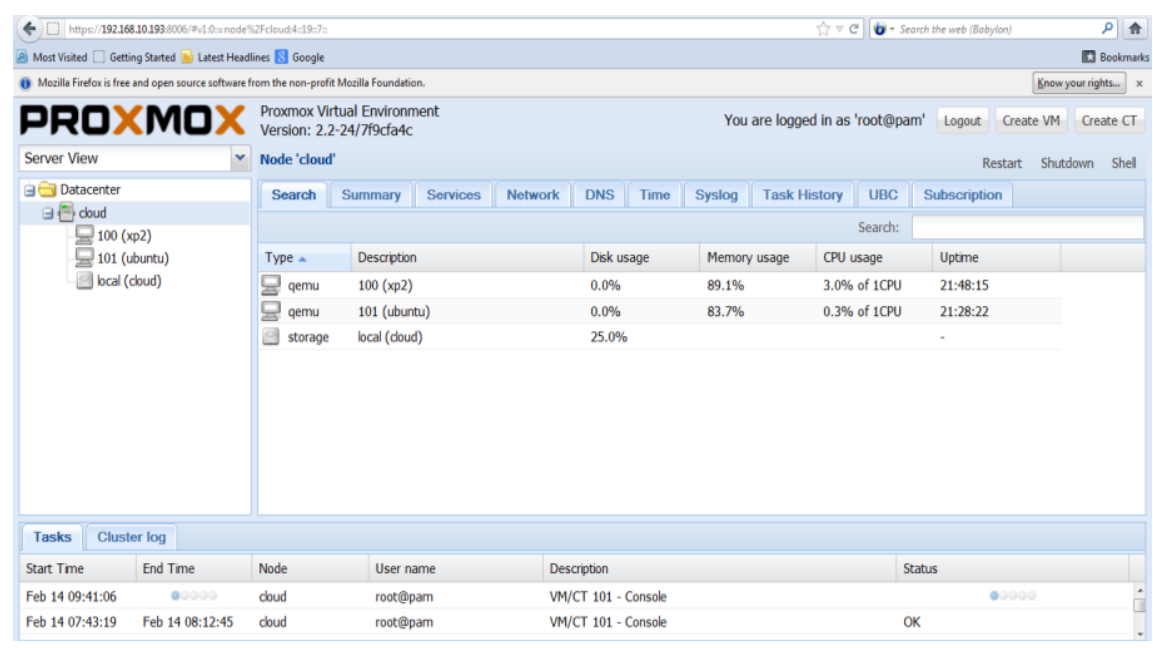

Gambar 6. Instalasi VPS1 dan VPS2 
Instalasi jaringan dibutuhkan untuk address VPS1 digunakan IP 192.168.10.194 mengkoneksikan tiap-tiap VPS yang ada dan VPS2 dengan IP 192.168.10.195.

kepada jaringan lokal. Untuk alamat IP

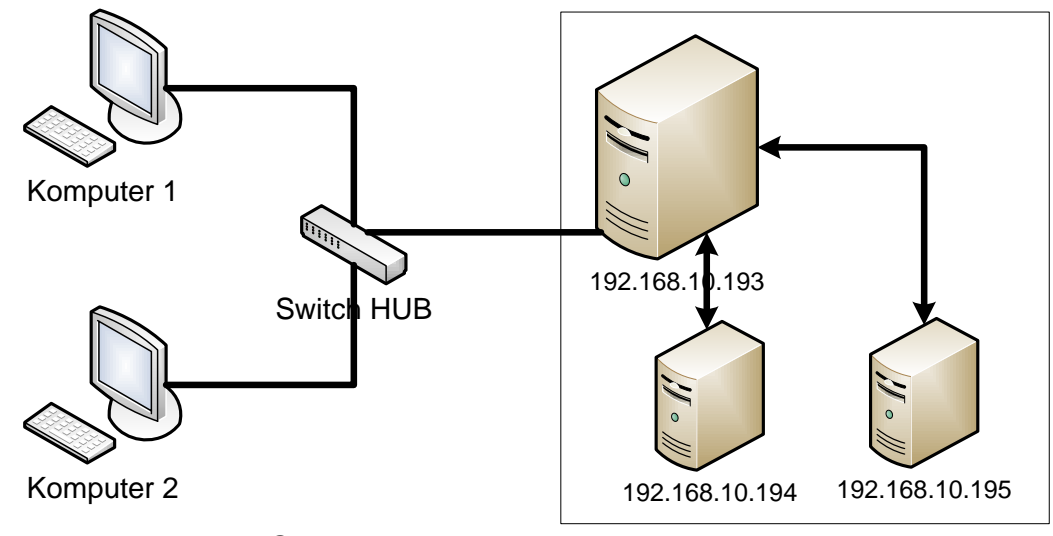

Gambar 7. Implementasi IP addres

Implementasi server database virtual pada tiap-tiap VPS. Setelah database MySql dilakukan setelah Virtual Private Server terinstal dalam VPS1 maka backup database terbentuk. Database yang digunakan di dalam dapat di restore kembali dengan virtual private server adalah database MySql. menggunakan remote database.

Instalasi database MySql harus dilakukan

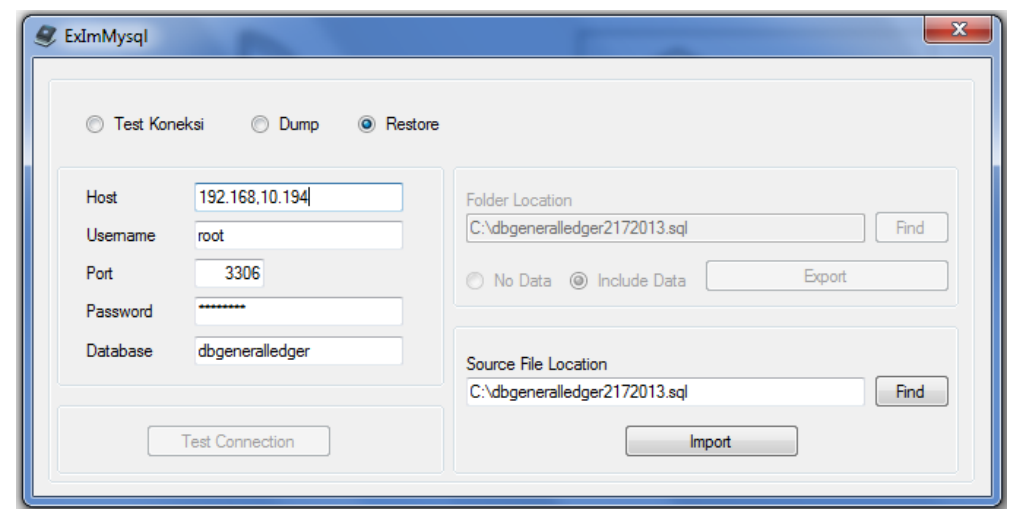

Gambar 8. Remote Database VPS1

\subsection{Pengujian Sistem}

Setelah database dapat ter-restore maka perlu dilakukan pengujian koneksi sistem aplikasi existing dengan server VPS1. Cara yang dilakukan adalah melalui test koneksi yang tersedia dalam sistem aplikasi existing. 


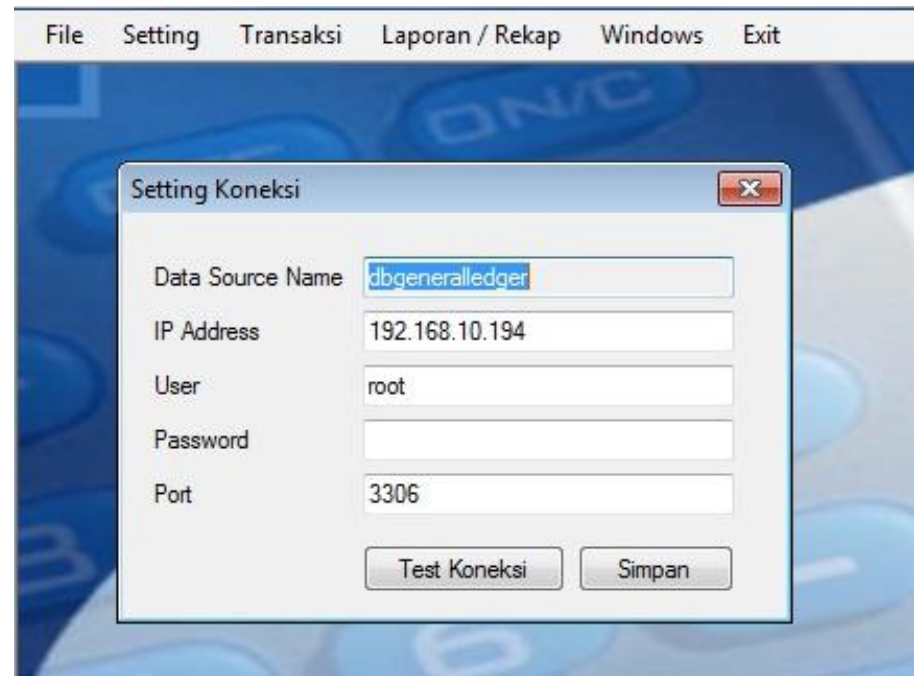

Gambar 9. Koneksi sistem aplikasi exisitng dengan VPS1

Untuk implementasi aplikasi baru maka perlu dilakukan pembuatan database dalam VPS2 atau dengan me-restore backup database projek seperti halnya, saat dilakukan restore pada VPS1. Setelah database terrestore maka perlu dilakukannya test koneksi untuk memastikan aplikasi terkoneksi dengan database yang ada dalam VPS2.

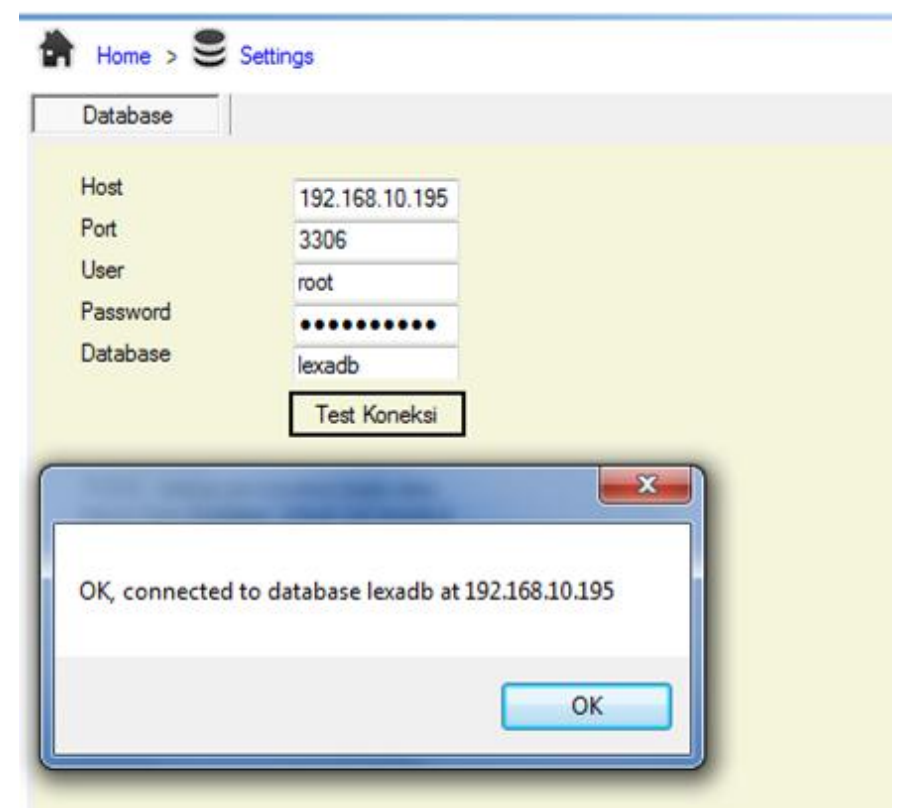

Gambar 10. Koneksi Sistem Informasi Baru dengan VPS2

Setelah dapat terkoneksi antara sistem informasi di komputer klien dengan VPS2 maka sistem secara otomatis dapat digunakan untuk ujicoba implementasi sistem baru tanpa harus membebani sistem exisitng. Dengan terbentuknya VPS1 dan VPS2 maka sistem aplikasi dapat berjalan secara parallel dalam satu komputer server exixting. 


\section{KESIMPULAN}

Dalam penelitian ini dapat ditarik beberapa kesimpulan yaitu

1. Pembangunan sistem ini telah berhasil dilakukan dengan membangun virtual private server untuk tiap-tiap sistem operasi. Virtual private server dibangun dengan melihat kebutuhan minimal dari tiap-tiap sistem operasi yang akan diinstal kedalam komputer existing.

2. Penggunaan virtual private server dengan model kernel-based virtual machine sangat mempermudah dalam pembuatan virtualisasi server. Virtual private server telah dibangun dan sistem aplikasi existing dan baru telah berjalan dengan baik sehingga implementasi virtual private server dengan model kernel-based virtual machine telah berhasil dilakukan.

3. Penggunaan virtual private server merupakan solusi untuk melakukan penghematan anggaran dalam pengadaan perangkat keras. Selain digunakan untuk penghematan anggaran perangkat keras, virtual private server dapat digunakan untuk penghematan anggaran lainnya seperti untuk biaya tenaga listrik, biaya tenaga kerja maintenance dan biaya pengadaan lokasi yang lebih besar.

\section{DAFTAR PUSTAKA}

[1] Alimuddin Zarkasyi, Sholiq, Rancang Bangun Aplikasi Pemesanan VPS Secara Online di PT. Ternakblog, Jurnal Teknik ITS Vol. 1, (September 2012) ISSN : 2301-9271, diunduh 30 Januari 2013.

[2] Arief Arfriandi, Perancangan, Implementasi dan Analisis Kinerja Virtualisasi Server menggunakan Proxmox, Vmware Esx dan Openstack, Jurnal Teknologi : Volume 5 Nomor 2, Desember 2012, 182-191 diunduh 30 Januari 2013.

[3] Hendarmawan, Desain, Implementasi dan Analisa Perfomasi Xen Hypervisor Virtual Machine Monitor Berbasis Linux
Untuk Solusi Teknologi Server di Indonesia, Jurnal Pointer, Vol 2, No. 1 (2011), diunduh 21 Februari 2013.

[4] K. Adams \& O. Agesen, A Comparison of Software and Hardware Techniques for $x 86$ Virtualization, http://www.vmware.com/pdf/asplos235 adams.pdf, 2006, retrieved may 11,2007

[5] M. V. Sugianto, Panduan Virtualisasi \& Cloud Computing pada Sistem Linux, Bekasi, 2011

[6] M.T. Jones, Virtual Linux, An overview of virtualization methods, architectures, and implementations, IBM developer

Works,

http://www.ibm.com/developerworks/linu x/library/linuxvirt, 2006, retrieved April

28, 2007

[7] Novan Ardianto, Widyawan, Sujoko Sumaryono, Pengembangan Virtual Appliance Server dengan Metode Virtualisasi, Jurnal Nasional Teknik elektro dan Teknologi Informasi Universitas Gadjah Mada, Vol.1 No.1, Mei 2012 ISSN : 2301-4156, diunduh 21 Februari 2013

[8] Rio Rasian, Petrus Mursanto, Perbandingan Kinerja Pendekatan Virtualisasi, Journal of Information system, Volume 5, Issues 2, Oktober 2009, diunduh 21 Februari 2013

[9] Seok-Pil Lee, Eui-Seok Nahm, A new Approach to Modeling of Linux Virtual Server based on Permormance Metrics Using an Optimal Load Balancing Algorithm, International journal of software Engineering and Its Application, Vol. 6, No. 2, April, 2012, diunduh 21 Februari 2013.

[10] Sugeng W., Jaringan Komputer dengan TCP/IP, Modula, Bandung 2010.

[11] Teguh Indra Bayu, Indrastanti Ratna Widiasari, Dian W. Chandra, Penerapan Teknologi Virtualisasi Tingkat Sistem Operasi pada Server Linux Ubuntu 8.04 menggunakan OpenVZ, Jurnal Teknologi Informasi - Aiti, Vol. 7 No.1, 
Februari 2010: 1-100, diunduh 21 Februari 2013.

[12] Tito Suryono, Mohammad Faruq Afif, Pembuatan Prototype Virtual Server menggunakan Proxmox Untuk
Optimalisasi Resource Hardware di NOC FKIP UNS, IJNS - Volume 1 Nomor 1 - November 2012, diunduh 30 Januari 2013. 